\title{
The Physicochemical and Nanotechnological Approaches to Creation of "Rigid" DNA Nanoconstructions
}

\author{
Yu. M. Yevdokimov ${ }^{\text {a, }}$, V. I. Salyanov ${ }^{\text {a }}$ E. V. Shtykova ${ }^{\text {b }}$ N. G. Khlebtsov ${ }^{\text {c }}$ E. I. Kats ${ }^{\text {d }}$ \\ and S. G. Skuridin ${ }^{\mathrm{a}}$ \\ ${ }^{a}$ Engelhardt Institute of Molecular Biology of the Russian Academy of Sciences, Vavilov str. 32, Moscow 119991, Russia \\ ${ }^{b}$ Shubnikov Institute of Crystallography of the Russian Academy of Sciences, Leninsky prospect 59, Moscow 119333, \\ Russia \\ ${ }^{c}$ Institute of Biochemistry and Physiology of Plants and Microorganisms of the Russian Academy of Sciences, Prospect \\ Entuziastov 13, Saratov 410049, Russia \\ ${ }^{d}$ Landau Institute for Theoretical Physics of the Russian Academy of Sciences, Kosygin str. 2, Moscow 119334, Russia
}

\begin{abstract}
Two different approaches to the creation of "rigid" (gel-like) DNA particles (or DNA nanoconstructions) are considered. The physicochemical approach is based on the formation of nanobridges between double-stranded DNA molecules ordered in quasinematic layers of cholesteric liquid-crystalline dispersion (CLCD) particles or their salting-out. This approach represents by itself a "chemical gelation" of DNA molecules realized inside the nanometric DNA particles. The formed "rigid" DNA particles have unique physicochemical properties. The nanotechnological approach is based on induction of "physical gelation" as a result of the formation of Au-clusters in the "free" space between double-stranded DNA molecules ordered in CLCD particles. This approach results in the formation of a new "rigid" DNA material. Its distinctive peculiarity, in contrast to the chemically bonded "rigid" DNA particles, consists in a very weak binding affinity to the nuclear membrane filter used for atomic force microscopy. This opens up a possibility for easy manipulations with CLCD particles doped with gold nanoparticles.
\end{abstract}

Keywords: DNA liquid-crystalline dispersions, nanoconstructions of DNA, nanotechnology of nucleic acids, structure of DNA liquid crystals.

\section{INTRODUCTION}

In recent years, many efforts have been devoted to the development of new materials considering the doublestranded (ds) DNA molecules just as a functional polymer. In some cases, practical application of these materials requires the transformation of linear ds DNA molecules into a gel-like, water-insoluble state. For instance, the insolubilization of individual salmon DNA molecules was realized by their cross-linking with UV irradiation or by forming molecular complexes with other chemical compounds [1,2].

However, in physicochemical terms the transformation of "liquid" particles of the DNA liquid-crystalline dispersions (LCD) into a "rigid" (gel-like) state seems to be more perspective in comparison to the insolubilization of individual DNA molecules $[1,3]$.

In our work, we briefly describe physicochemical approaches for the creation of "rigid" (gel-like) DNA particles

*Address correspondence to this author at the Engelhardt Institute of Molecular Biology, Russian, Academy of Sciences, Vavilov str. 32, Moscow, 119991 Russia; Tel: 8-499-135-97-20; Fax: 8-499-135-14-05;

E-mail: yevdokim@eimb.ru
(DNA nanoconstructions) and focus mainly on the new nanotechnological approach based on doping of ds DNA cholesteric liquid-crystalline particles with gold nanoparticles (nano- $\mathrm{Au}$ ).

Hence, a few important peculiarities of the LCDs formed as a result of phase exclusion of linear ds DNA molecules from polymer-containing solutions (for instance, polyethyleneglycol, PEG) should be mentioned at the beginning.

It was shown in our previous work [4] that in the case of ds DNA molecules (a mean molecular mass is about $0.8 \times 10^{6}$ $\mathrm{Da}$, that corresponds to a mean length of the DNA molecules about $400 \mathrm{~nm}$ ), each particle of LCD has a mean diameter about $400-500 \mathrm{~nm}$. It contains about $10^{4}$ ds DNA molecules. The neighboring DNA molecules, whose negatively charged phosphate groups are neutralized by cations, are ordered in the LCD particles with characteristic interparticle distance of 2.5-5.0 nm (depending on osmotic pressure of the solvent), i.e. they acquire crystalline properties. Besides, these molecules maintain almost all of the essential diffusion freedom, they exist in a "soluble" state, i.e., they retain the liquid properties. Such combination of properties allows this structure to be defined as "liquid-crystalline" (see [3,4] and early references cited therein). (Every neighboring layer in this 


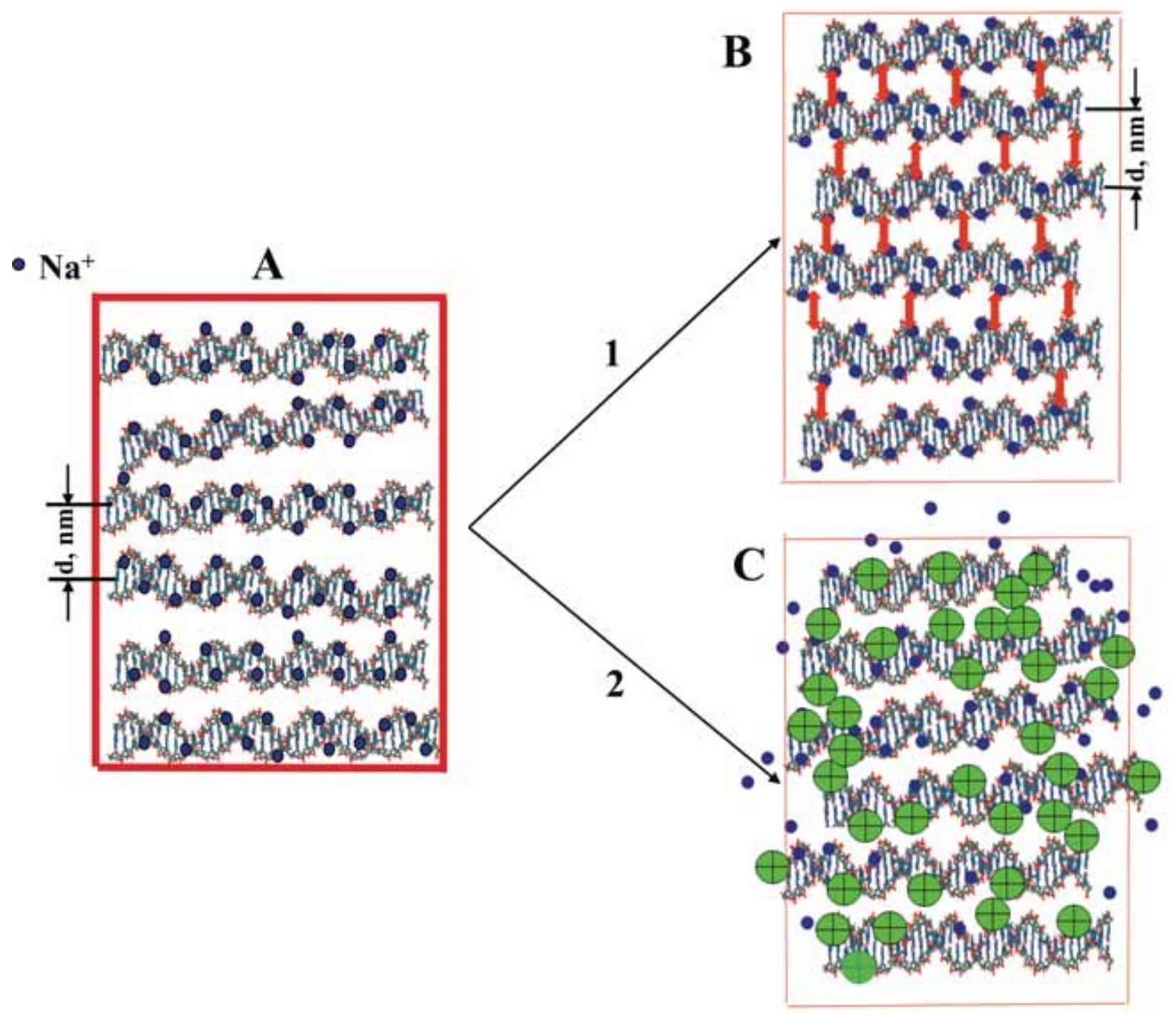

Fig. (1). A. Structure of quasinematic layer formed by ds DNA molecules in particle of LCD.

DNA molecules are ordered and the mean distance between these molecules is expressed as d value, which depends on osmotic pressure of solvent (thick red frame is symbol of osmotic pressure). Between DNA molecules there is a "free" space. The low-molecular mass chemicals or biologically active compounds ("guests") can easily diffuse from outside into "free" space of quasinematic layers.

B. Hypothetical scheme of transformation of a "liquid" structure of quasinematic layer formed by ds DNA molecules into a "rigid" state. The crosslinks (nanobridges) are formed both between DNA molecules in one and neighboring quasinematic layers. At certain nanobridges amount and their "rigidity" the integrated structure that includes all ds DNA molecules is formed. The formed "rigid" spatial structure is capable of existing under a very low osmotic pressure of solution (shown as thin red frame).

C. Hypothetical scheme of transformation of a "liquid" structure of quasinematic layer formed by ds DNA molecules into "rigid" state as a result of "salting-out" of these molecules.

The multivalent cations ( $\mathrm{R}^{\mathrm{N}+}$, "guests") diffuse into layer and form insoluble complexes with the DNA phosphate groups. Concentration of sodium cations is decreased, but concentration of "guests" is sharply increased in a quasinematic layer. Close approaching of all insoluble ds DNA molecules results in formation of integrated DNA structure, which can exist at low (if any) osmotic pressure of the solvent (shown as thin red frame).

structure is called a "quasinematic layer" in the physics of liquid crystals [5]). Since ds DNA molecules contain chromophores (nitrogen bases) theoretical calculations [6, 7] show that an appearance of a very intense (abnormal) negative band in the CD spectrum at $\lambda \sim 270 \mathrm{~nm}$ univocally testifies macroscopic (cholesteric) twist of neighboring quasinematic layers of ds DNA molecules in LCD particles. In order to stress this peculiarity, the term DNA "cholesteric liquidcrystalline dispersions" (CLCD) or "DNA cholesterics", was used to signify these particles $[8,9]$.

\section{RESULTS AND DISCUSSION}

\subsection{The Physicochemical Approaches to the Creation of "Rigid" DNA Particles (DNA Nanoconstructions)}

The polymer physical chemistry allows one [10] to prove that there are only two approaches for transformation of liquid-crystalline DNA particles (Fig. 1-A) into their "rigid" (gel-like) state (Fig. 1). 
First version of the formation of "rigid" nano-objects from ds DNA molecules is illustrated in Fig. (1-B).

This approach is based on the following points: "ds DNA molecules ordered in quasinematic layers of CLCD particles exist in a "soluble" state, and there is "free" space between these molecules. The "guest" molecules can diffuse into the "free" space without affecting the ordered arrangement of the DNA molecules. However, "guests" molecules can cross-link neighboring ds DNA molecules. These cross-links (nanobridges) can be formed both between ds DNA molecules in one quasinematic layer and in neighboring layers. At a certain amount of nanobridges integrated high-molecular mass structure containing all DNA molecules ordered in one CLCD particle can be formed. This structure is not compatible with initial polymer containing solution. This means that the cross-linking of ds DNA molecules can induce the transition from "liquid" to "rigid" (gel-like) state of dispersion particle".

Hence, "rigid" spatial DNA nanoconstruction $(\mathrm{NaC}$, nano-object) containing "guest" molecules may be created.

The proposed approach was tested, at first, experimentally $[11,12]$, then theoretically $[13,14]$ and, finally, all results obtained were analyzed in [15]. It has been shown that the nanobridges are composed of alternating anthracycline antibiotic - daunomycin (DAU) and copper ions cross-link the ds DNA molecules located both in one and in neighboring quasinematic layers of CLCD particle. This mode of gelation dramatically changed the properties of CLCD particles and allowed us to produce "rigid" particles. The formation of "rigid" particles sharply increases the amplitude of abnormal negative band in the $\mathrm{CD}$ spectrum in the absorption region both of the DNA $(\lambda \sim 270 \mathrm{~nm})$ and DAU chromophores $(\lambda \sim 505 \mathrm{~nm})$ [15]. The stability of "rigid" DNA particles depends on the properties of the nanobridges, not on the osmotic pressure of solution [15]. The result of the AFM studies of the "rigid" DNA particles allows one to perform some important evaluations [3]. It was confirmed that one "rigid" particle contains $1.6 \times 10^{4}$ ds DNA molecules, the molecular mass of one DNA "rigid" particle is equal to $(1.0-1.2) \times 10^{10}$ $\mathrm{Da}$. These values based on the direct AFM measurements are close enough to the values obtained earlier for the particles of DNA LCDs formed at the phase exclusion of these molecules (its molecular mass is equal to $4.76 \times 10^{10} \mathrm{Da}$. Finally, it has been shown that the packing density of DNA nitrogen bases (chromophores) is close to 1 chromophore per $1 \mathrm{~nm}^{3}$.

Hence, cross-linking of ds DNA molecules by nanobridges, accompanied by formation of the integrated structure, induces transition of the whole ds DNA CLCD particles from "liquid" to "rigid" state, i.e. NaCs formation [15].

The second version of the formation of spatial nanoobjects from ds DNA molecules is illustrated in Fig. (1-C).

The basic problem can be formulated as follows: "ds DNA molecules ordered in quasinematic layers of CLCD particle exist in a "soluble" state, and between these molecules there is "free" space. Multivalent cations can diffuse into "free" space and form insoluble complexes with phosphate groups of all ds DNA molecules. This results both in decrease in the solubility of every ds DNA (or even fragments of neighboring DNA molecules) and in "salting-out" of all ds DNA molecules ordered within quasinematic layers of CLCD particle. Due to heterogeneous secondary structure of ds DNA molecules, an irregular attraction between insoluble DNA molecules (or their fragments) in quasinematic layers should lead to the formation of integrated spatial structure consisting of all DNA molecules which is incompatible with polymer-containing solution. It indicates a phase transition of ds DNA CLCD particles from "liquid" to "rigid" (gel-like) state".

In physicochemical terms, this approach differs from the gel formation described above, because it is based not on DNA chemical cross-linking but on the "physical" gelation due to interaction between insoluble ds DNA molecules within CLCD particles.

Cations of rare earth elements (REE) are of special interest from the standpoint of making the ds DNA molecules in quasinematic layers poorly soluble. These cations were used for realization of this version [16-18]. It was shown that the treatment of ds DNA CLCD with gadolinium salt $\left(\mathrm{GdCl}_{3}\right)$ is accompanied by increase in amplitude of negative abnormal band $(\lambda \sim 270 \mathrm{~nm})$ in the CD spectrum [16]. This amplification of the band is similar to that observed upon crosslinking of neighboring DNA molecules due to nanobridge formation.

Thus, one can expect that CLCDs of ds DNA with all phosphate groups neutralized by $\mathrm{Gd}^{3+}$ ions, become poorly soluble and can exist even in absence of high osmotic pressure of PEG-containing solution [17]. Considering that these ds DNA molecules cannot "leave" the physical volume of CLCD particle and that separation of ds DNA chains in these particles is impossible for steric reasons due to fixed osmotic pressure of PEG-containing solution, we come to the following conclusion. The disappearance of the fluidity of individual ds DNA molecules, combined with an increase in shortrange attractive interaction between their fragments with different conformations, induces the transition of overall structure of CLCD particles from "liquid" to "rigid" state [17].

The results of AFM measurements show that treatment of ds DNA CLCD particles with the gadolinium salt is not accompanied by alteration in the mean size of the "rigid" $\mathrm{NaCs}$ of (DNA-Gd) complexes [16-18].

The results of X-ray measurements show that treatment of DNA CLCD particles with gadolinium salts leads to the onset of a modified secondary structure of ds DNA molecules and to the alteration of the helical twist of the cholesteric structure [17]. The last effect is responsible for amplification of intense negative band in the CD spectrum [7].

Hence, "salting-out" of ds DNA molecules in CLCD particles, accompanied by incompatibility of formed integrated structure with polymer-containing solution, induces the transition from "liquid" to "rigid" state of ds DNA CLCD particles, i.e. DNA NaCs formation.

The results presented above allow one to conclude that the physicochemical approaches to creation of "rigid" nanoobjects from ds DNA molecules are limited only to two considered items. 


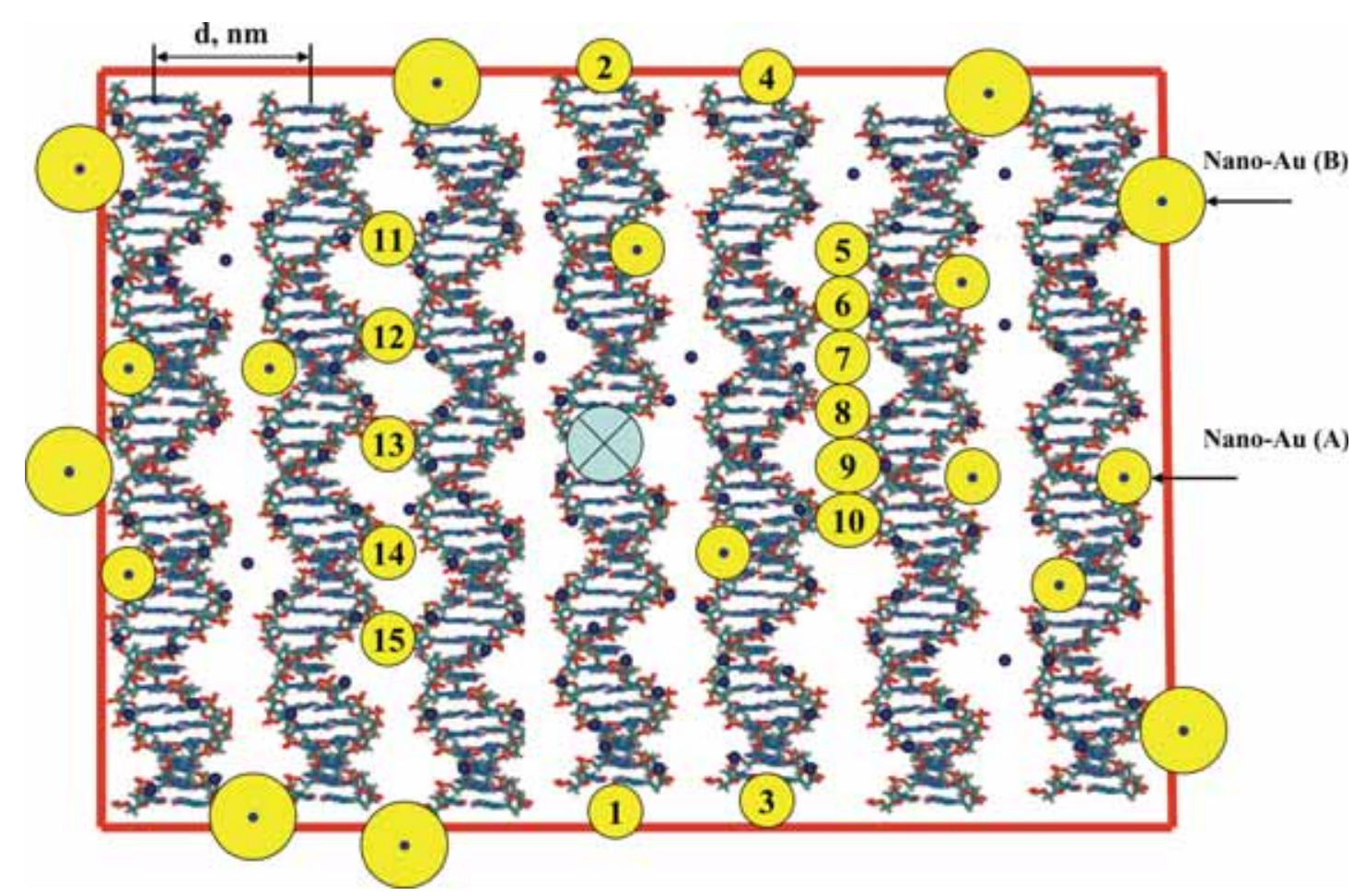

Fig. (2). Hypothetical scheme of spatial disposition of different size (A, B) nano-Au near of ds DNA molecules forming a quasinematic layer.

Red rectangular frame shows osmotic pressure of PEG-containing solution; $d$ - distance between axes of neighboring DNA molecules.

\subsection{The Nanotechnological Approach to Creation of "Rigid" DNA Particles (DNA Nanoconstructions)}

Nanotechnology opens a new way for "rigid" DNA NaCs formation. Indeed, a new trend in nanotechnology, which even does not yet have a title, is promptly developing. It is related to the formation of new materials incipient in system (nanoparticles - liquid crystals of low-molecular mass compounds) [19]. Though first nanoparticles used in such systems were carbon nanotubes, nano-Au or nanoparticles with gold "core" [20,21] are often utilized nowadays. As a result of such processing not only the physicochemical properties of low molecular mass liquid crystals can be varied [22-24] but one can get a specific ordering of nanoparticles in liquid crystals [25].

Concerning the liquid crystals made of biopolymers (e.g., of DNA molecules), such systems were handled both with carbon nanotubes [26] and with nano-Au. The latter investigations have been started in 2010 [27], although properties of linear DNA molecules containing ordered nano-Au on their surface were studied since the first influential papers (1996) in this field by C.A. Mirkin and P.A. Alivisatos [28, 29].

Our goal is the creation of "rigid" particles from highmolecular mass DNA CLCD particles doped with nano-Au.

\subsubsection{Changes in CD Spectra Caused by the Doping of DNA CLCD Particles with Nano-Au}

Analyzing the properties of a quasinematic layer of DNA CLCD particles (Fig. 2) possible mechanisms of interaction of nano-Au with DNA CLCD particles can be hypothesized.
First, a single nano-Au of any size (A and $\mathbf{B})$ can form complexes with nitrogen base pairs (namely, N7 atoms of purine, N3 atoms of pyrimidine [30-32]) of "surface" DNA molecules. The efficiency of the formation of these complexes can depend on the size of nano-Au. Basically, such complexes do not necessarily perturbate the structure of quasinematic layers of DNA molecules. The formation of dipoles (Fig. 2, nano-Au 1-2 and 3-4) as the result of the binding of nano-Au with terminal sites of DNA molecules plays a more significant role. Dipoles of adjacent (DNA-nano-Au) complexes will tend to orient in parallel and may induce changes in the spatial helical twist of quasinematic layers. It means that nano-Au may cause changes in some molecular interactions (e.g., the anisotropic part of the van Der Waals interaction) that determine the helical twist of adjacent quasinematic layers of DNA molecules without having a significant effect to the other forces (steric, etc.) that determine the parallel (nematic-like) orientation of neighboring DNA molecules. In this case, the twist angle between layers $\left(\sim 0.1^{\circ}[4]\right)$ may vanish, which is equivalent to unwinding of the cholesteric structure of the dispersion [7]. Moreover, one can suppose that nano-Au with the size comparable to the distance $[3,4]$ between DNA molecules in quasinematic layers can diffuse between these molecules (Fig. 2). The interaction between reactive groups of ds DNA molecules and nano-Au can be the factor that responsible for spatial fixation of nano$\mathrm{Au}[32,33]$.

It has to be highlighted that the effective interaction between nano-Au can be mediated via adjacent DNA molecules [3]. These factors can both affect the possibility of ordering of nano-Au (formation of various linear Auassemblies; (Fig. 2, compares nano-Au 5-10 and 11-15)) and 


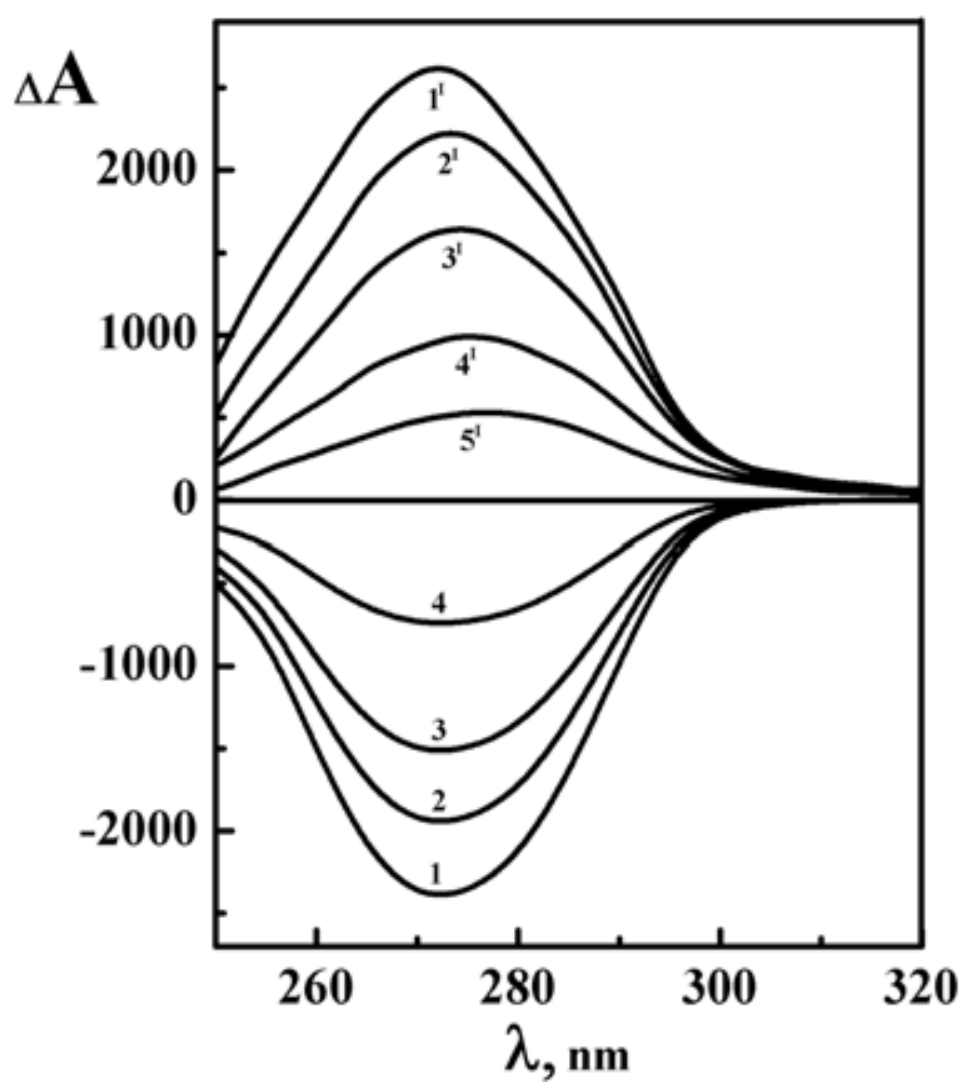

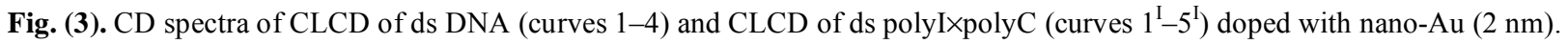
$1-\mathrm{C}_{\text {nano-Au }}=0 ; 2-\mathrm{C}_{\text {nano-Au }}=0.07 \times 10^{14} ; 3-\mathrm{C}_{\text {nano-Au }}=0.26 \times 10^{14} ; 4-\mathrm{C}_{\text {nano-Au }}=0.82 \times 10^{14}$ particles $/ \mathrm{mL}$.

$\mathrm{C}_{\mathrm{DNA}}=9 \mu \mathrm{g} / \mathrm{mL} ; \mathrm{C}_{\mathrm{PEG}}=150 \mathrm{mg} / \mathrm{mL} ; 0.27 \mathrm{M} \mathrm{NaCl}+1.78 \times 10^{-3} \mathrm{M} \mathrm{Na}^{+}$-phosphate buffer.

$1^{\mathrm{I}}-\mathrm{C}_{\text {nano-Au }}=0 ; 2^{\mathrm{I}}-\mathrm{C}_{\text {nano-Au }}=0.16 \times 10^{14} ; 3^{\mathrm{I}}-\mathrm{C}_{\text {nano-Au }}=0.33 \times 10^{14} ; 4^{\mathrm{I}}-\mathrm{C}_{\text {nano-Au }}=0.66 \times 10^{14} ; 5^{\mathrm{I}}-\mathrm{C}_{\text {nano-Au }}=0.82 \times 10^{14}$ particles $/ \mathrm{mL}$.

$\mathrm{C}_{\text {polyI } \times \text { polyC }}=9 \mu \mathrm{g} / \mathrm{mL} ; \mathrm{C}_{\mathrm{PEG}}=170 \mathrm{mg} / \mathrm{mL} ; 0.27 \mathrm{M} \mathrm{NaCl}+1.78 \times 10^{-3} \mathrm{M} \mathrm{Na}^{+}$-phosphate buffer.

$\Delta \mathrm{A}=\left(\mathrm{A}_{\mathrm{L}}-\mathrm{A}_{\mathrm{R}}\right) \times 10^{-6}$ optical units; $1=1 \mathrm{~cm}$.

cause a local perturbation of orientation order parameter of DNA molecules. The factors mentioned above depend on the concentration of nano-Au and properties of their surface; they determine both the average distance between adjacent nanoparticles and the size of the forming Au-assemblies.

It is worth noticing that properties typical for small nano$\mathrm{Au}[34,35]$, the fixation of the nanoparticles in quasinematic layers of DNA molecules may cause two optical effects. Firstly, a perturbation of the cholesteric structure of LCD particles followed by a change in their abnormal optical activity may take place. Secondly, certain configurations of adjacent nano-Au within the DNA quasinematic layers can be accompanied by an appearance of a localized surface plasmon resonance (SPR) band in the absorption spectrum that is characteristic of the assembles (clusters) of these nanoparticles.

The CD spectra of various ds NA CLCD particles doped with nano-Au $(\mathrm{d} \sim 2.0 \mathrm{~nm})$ are shown in Fig. (3). (We have used hydrosol containing quasi-metallic nano-Au of 2-3 nm in diameter obtained according to well-known procedure. The $\xi$-potential of nano-Au was about $-(30-40) \mathrm{mV}$, i.e. the nano-Au were negatively charged). One can see that the amplitudes of the bands drop sharply at the increase of the concentration of chemically synthesized nano-Au in the solution
[27]. The decrease in the amplitude of the abnormal band in the DNA CLCD CD spectrum starts at the critical concentration of nano-Au, which is approximately 1,000 nano-Au per one DNA CLCD particle and depends on the size of nano$\mathrm{Au}$ [3]. Such decrease in optical activity confirms the unwinding of the particle spatial structure regardless of the origin of nucleic acids [7]. This effect is unique as none of the other chemical or biological compounds can cause the nematization (complete unwinding) of the spatial structure of CLCD particles as a result of their interaction with DNA molecules at the room temperature. Obtained results demonstrate unambiguously that ds DNA molecules, after they are doped with nano-Au, are collinearly arranged in order to form planar suprastructures [36-39] despite the fact that DNA molecules possess chiral and anisotropic properties.

\subsubsection{Changes in the Absorption Spectrum Caused by the Doping of DNA CLCD Particles with Nano-Au}

As DNA CLCD particles are doped with small $(\sim 2 \mathrm{~nm})$ nano-Au the changes in both visible and UV region of the absorption spectrum are observed (Fig. 4). The feebly marked band $\mathbf{I}$ at $505 \mathrm{~nm}$ (SPR band) is changed. The amplitude of SPR band increases in time and its location shifts from $\lambda \sim 505$ to $\sim 550 \mathrm{~nm}$. At the same time, amplitude of 


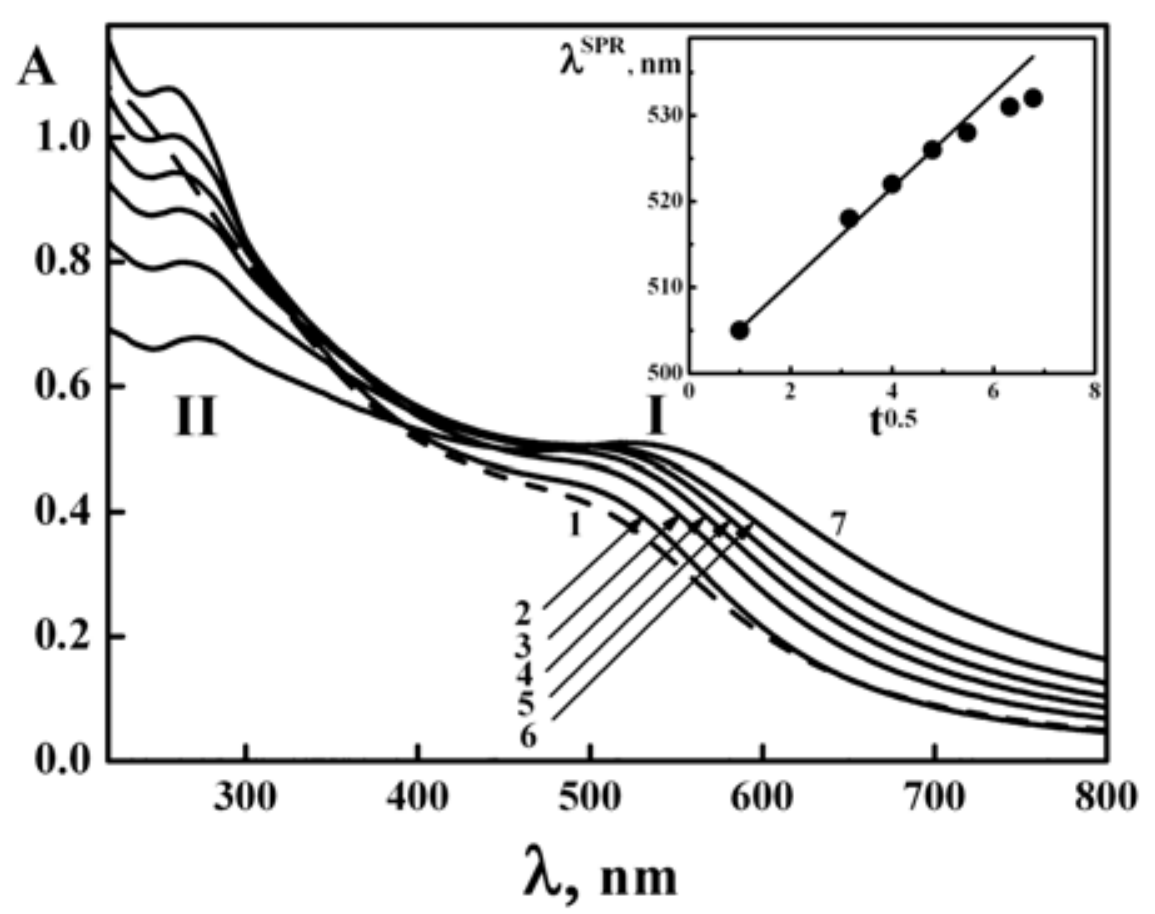

Fig. (4). Absorption spectra of ds DNA CLCD doped with nano-Au at different time: 2 - 1 min; 3 - 10 min; 4 - 23 min; 5 - 46 min; 6 - 148 $\min ; 7$ - $1320 \mathrm{~min}$.

$\mathrm{C}_{\mathrm{DNA}}=9.8 \mu \mathrm{g} / \mathrm{mL} ; \mathrm{C}_{\mathrm{PEG}}=170 \mathrm{mg} / \mathrm{mL} ; \mathrm{C}_{\text {nano-Au }}=0.17 \times 10^{15}$ particles $/ \mathrm{mL} ; 0.3 \mathrm{M} \mathrm{NaCl}+2 \times 10^{-3} \mathrm{M} \mathrm{Na}^{+}$-phosphate buffer.

Curve 1 (dashed) - absorption spectrum of water-salt PEG-containing solution after addition of nano-Au.

$\mathrm{C}_{\mathrm{PEG}}=170 \mathrm{mg} / \mathrm{mL} ; 0.3 \mathrm{M} \mathrm{NaCl}+2 \times 10^{-3} \mathrm{M} \mathrm{Na}^{+}$-phosphate buffer; $\mathrm{C}_{\text {nano-Au }}=0.17 \times 10^{15}$ particles $/ \mathrm{mL}$.

Inset: Dependence of the location of SPR band maximum in the absorption spectrum of DNA CLCD doped nano-Au versus $\mathrm{t}^{1 / 2}$ value $(\mathrm{t}$ - time, $\min$.).

band II in the UV region of the spectrum decreases in time. (According to the theoretical calculations [40] similar changes in bands I and II in the absorption spectrum correspond to the increase of the volume fraction of nano-Au in assemblies formed by these particles).

It can be hypothesized that the development of SPR band and the "red" shift of position of its maximum reflects the formation of nano-Au assemblies.

The important issues to be clarified: i) where are nano-Au forming assemblies and ii) what is the spatial shape of these assemblies. It can be assumed that small-sized nano-Au diffuse into CLCD particles and create spherical or linear nano-Au assemblies there.

The inset in (Fig. 4) shows the dependence of location of maximum of SPR band in the absorption spectrum of DNA CLCD doped with nano-Au versus $\mathbf{t}^{1 / 2}$ value $(\mathbf{t}-$ time $)$. It is important to note, that $\lambda^{\text {SPR }}$ (up to the moment of its saturation) is proportional to $\mathbf{t}^{\mathbf{1} 2}$ value. If we accept $[34,35]$ that the displacement of location of SPR band is connected with increase in size of nano-Au linear clusters, the theoretical estimation allows one to speculate about mechanism of these cluster formation inside ds DNA CLCD particles. It is known that the cluster growth is determined by the competition between bulk and surface free energies, which include the internal energy and the entropy of all colloidal particles participating in the cluster formation. At the analysis of this process, which was performed by Lifshitz and Sleozov [41] a long time ago, it has been shown that the size, $\mathbf{R}$, of a cluster of the spherical form increases proportionally to $\mathbf{t}^{1 / 3}$ value. Application of Lifshitz and Sleozov approach to the description of the growth of the cylindrical cluster shows that in this case the length, $\mathbf{L}$, of the cylinder is growing proportionally to $\mathbf{t}^{1 / 2}$ value (independent of the cylinder radius). This theoretical evaluation fits quite well the experimental data shown in (Fig. 4), which illustrates the change in the location of the SPR band in time, and speaks in favor of the formation of linear nano-Au clusters between ds DNA molecules in quasinematic layers.

In order to verify this assumption, "free space" between the neighboring DNA molecules in CLCD particles was filled with stable planar nanobridges (see above) consisting of alternating antibiotic molecules and copper ions (Fig. 5). As it was shown above, this process results in the formation of "rigid" DNA $\mathrm{NaC}$ (see subsections 2.1 and 2.2). In this case, "free space" becomes inaccessible for diffusion of nano-Au and therefore, formation of linear assemblies (linear clusters) is strongly suppressed. If the assumption about the localization of nano-Au clusters is valid, then the doping of the DNA $\mathrm{NaC}$ with nano-Au in such situation will not result in any changes in the bands located both in the UV and visible regions of the absorption spectrum. Indeed, experiments have shown that SPR band (I) in the absorption spectrum does not evolve in this case. Besides, band (II) in the UVregion of the spectrum remains virtually intact. This means that small-sized nano-Au cannot be inserted between the 


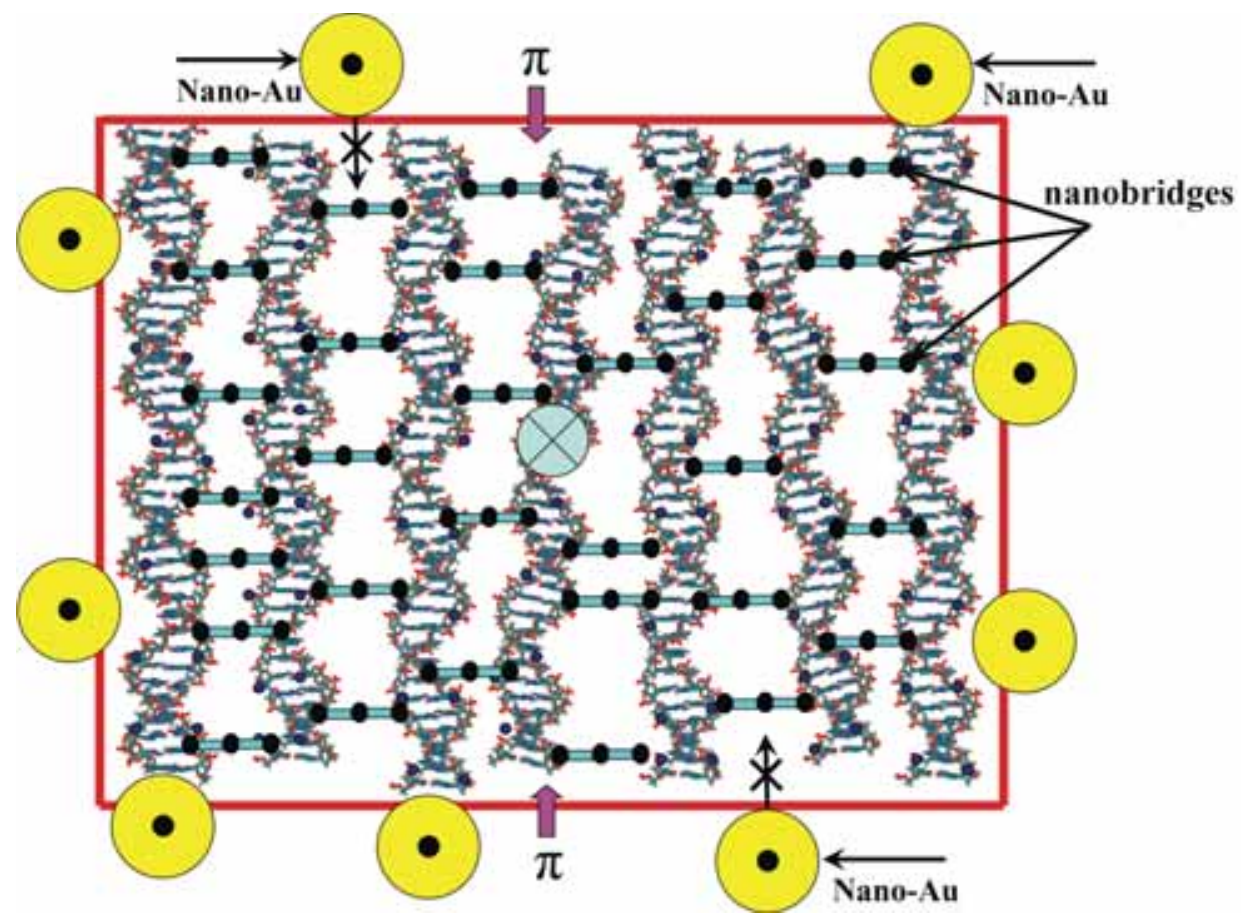

Fig. (5). Hypothetical structure of the quasinematic layer in "rigid" DNA nanoconstruction.The "free" space between the neighboring ds DNA molecules forming a quasinematic layer is filled with nanobridges, which do not allow nano-Au to penetrate into the layer and to form assemblies in "free" space (the probability of their interaction with "surface" DNA molecules remains unchanged). Frame means the presence of osmotic pressure of PEG-containing solution.
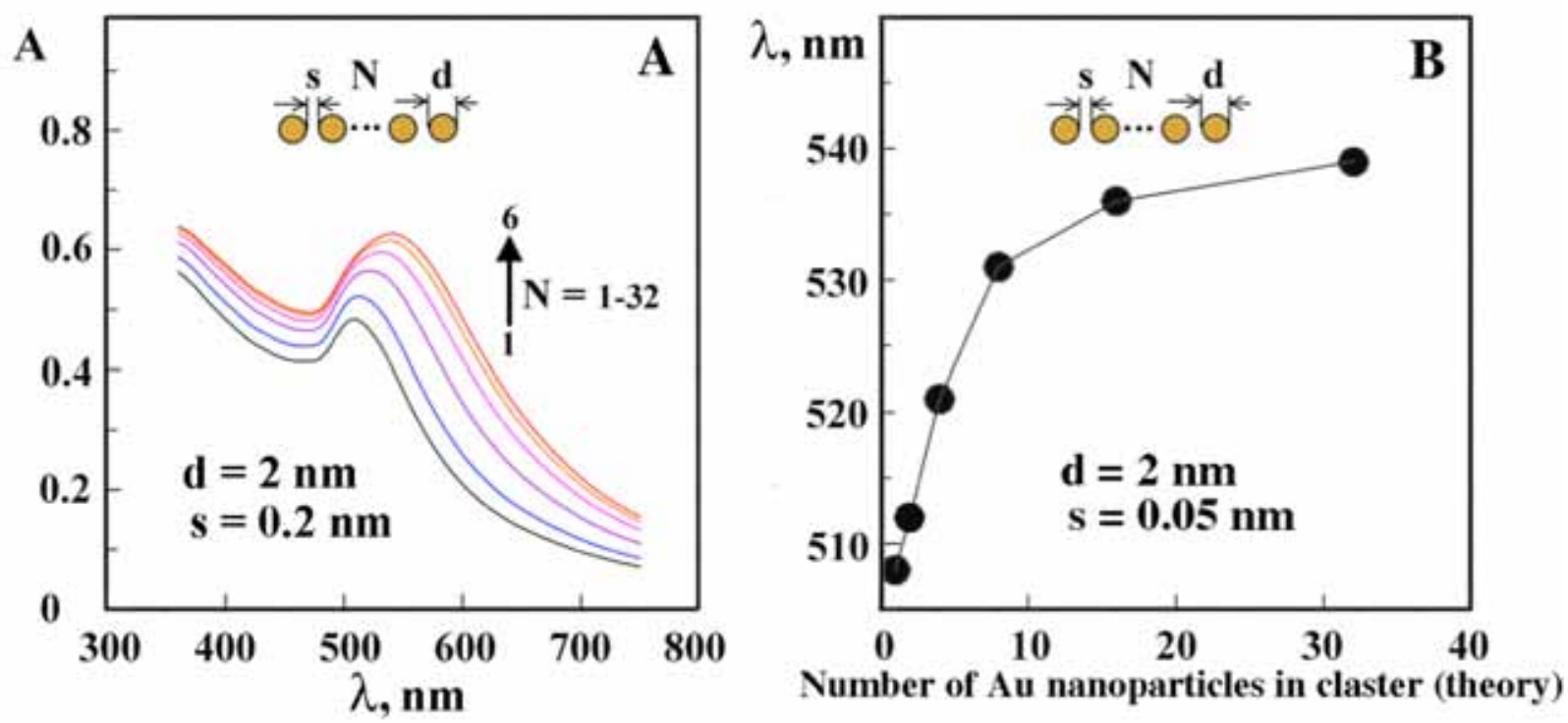

Fig. (6). A. The theoretically calculated normalized absorption spectra of nano-Au ( $2 \mathrm{~nm})$ linear clusters.

The distance between nano-Au $-0.2 \mathrm{~nm}$; the number of nano-Au in clusters $1 ; 2 ; 4 ; 8 ; 16$ and 32 (curves 1-6, respectively).

B. The theoretical dependence of location of SPR band maximum upon the number of nano-Au in linear clusters.

neighboring ds DNA molecules, since the "free" space is occupied by nanobridges. The obtained result confirms assumption on formation of linear nano-Au clusters between ds DNA molecules in quasinematic layers.

To check this statement again the absorption spectra of chaotically oriented assemblies of nano-Au $(2 \mathrm{~nm})$ linear clusters in water have been calculated. The number of nano-Au in clusters was varied from 1 to 32 , the distance between nano-Au was equal to $0.2 \mathrm{~nm}$. Hence, the size of clusters was in the range from 2 to about $65 \mathrm{~nm}$. The calculations were carried out by the T-matrix cluster method [42]; the indispensable details of calculation are described in works [43, 44].

One can see (Fig. 6) that the calculated spectra reproduce three basic experimental features: (1) an increase in the amplitude of the SPR band, (2) its "red" shift and (3) saturations 


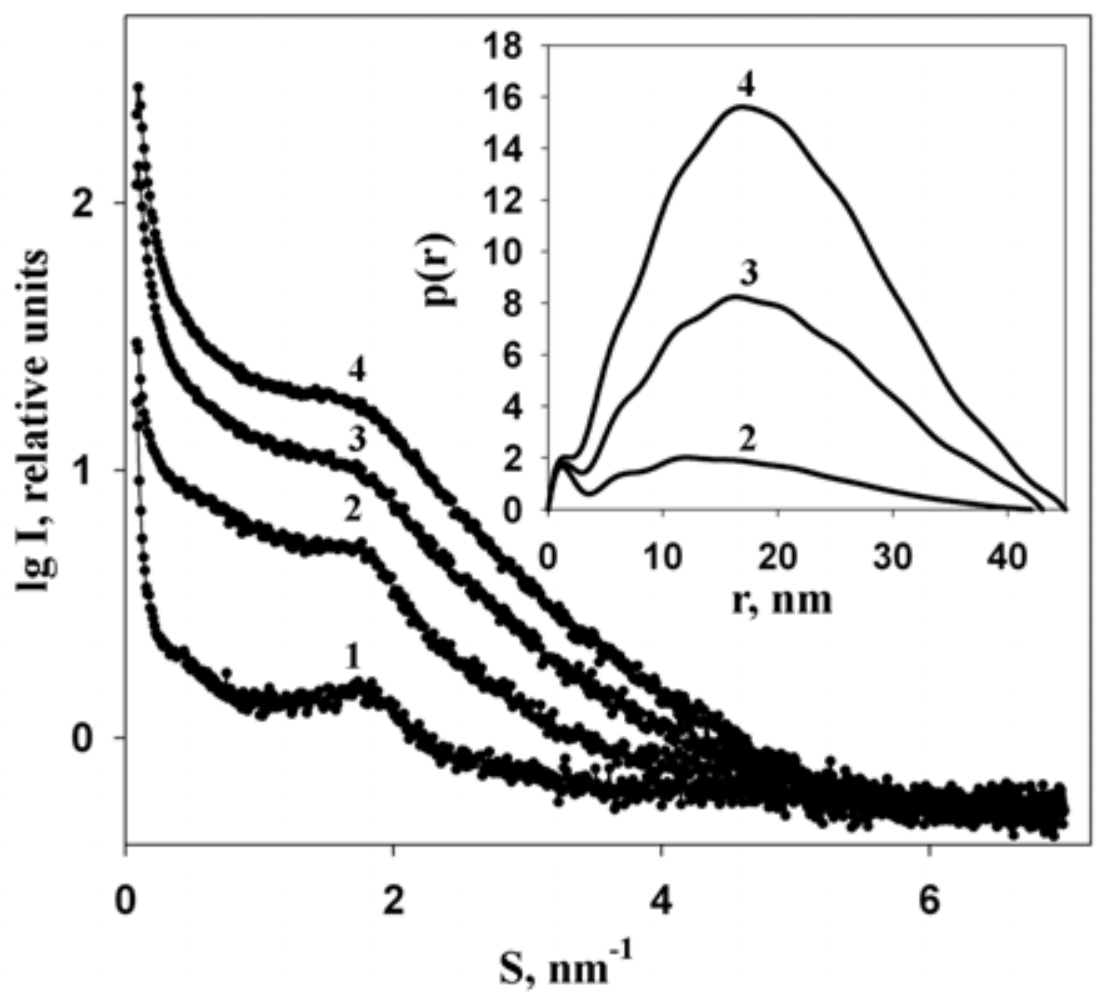

Fig. (7). Small-angle X-ray scattering curves of ds DNA cholesteric liquid-crystalline phase (curve 1, control) and of the ds DNA phases containing various nano-Au concentrations (curves 2-4).

Curve $1-\mathrm{C}_{\mathrm{nano}-\mathrm{Au}}=0$; curve $2-\mathrm{C}_{\text {nano-Au }}=0.07 \times 10^{14}$ particles $/ \mathrm{mL}$; curve $3-\mathrm{C}_{\text {nano-Au }}=0.33 \times 10^{14}$ particles $/ \mathrm{mL}$; curve $4-\mathrm{C}_{\mathrm{nano}-\mathrm{Au}}=$ $0.66 \times 10^{14}$ particles $/ \mathrm{mL}$.

$\mathrm{C}_{\mathrm{DNA}}=27 \mu \mathrm{g} / \mathrm{mL} ; \mathrm{C}_{\mathrm{PEG}}=150 \mathrm{mg} / \mathrm{mL} ; 0.27 \mathrm{M} \mathrm{NaCl}+1.78 \times 10^{-3} \mathrm{M} \mathrm{Na}^{+}$-phosphate buffer.

Inset presents the difference curves: 2 - (curve 2 - curve 1); 3 - (curve 3 - curve 1 ); 4 - (curve 4 - curve 1).

of dependence of the SPR variation at the increase of the nano-Au number in a cluster. Comparison of Fig. (6) to Fig. (4) shows that even the elementary model of linear clusters with only a single fitted parameter (interparticle distance) correctly describes total change in SPR band maximum location and its two-stage character.

Hence, the observed evolution of the SPR band (Fig. 4) is due to the formation of linear nano-Au clusters in the content of ds DNA CLCD particles. Formation of these clusters induces, first, the alteration in mutual orientation of neighboring quasinematic layers. Under these conditions, the helical twist of these layers decreases as it happens in case of low molecular mass liquid crystals [23, 24]. Second, the formation of nano-Au clusters between ds DNA molecules can increase interaction between these molecules and it results in the induction of the "physical" gelation of neighboring DNA molecules fixed in quasinematic layers of CLCD particle. Under these conditions the integrated structure, which consists of all DNA molecules inside one particle, is created. The diffusive mobility of DNA molecules decreases and solubility of this structure, which has now a very high molecular mass, drops. Formed unique integrated structure is not compatible with polymer-containing solution. Stability of this structure is determined by the number and properties of $\mathrm{Au}$-clusters rather than by properties of the initial PEG-containing solution [3]. If this is the case, the transition of "liquid" CLCD particle into insoluble ("rigid", gel-like) state takes place. This means that "rigid" structure would persist even in the absence of the high osmotic pressure of the solution and it opens a possibility to investigate properties of this structure.

\subsubsection{Small-angle X-ray Scattering of Phases Formed by ds DNA CLCD Doped with Nano-Au}

Taking into account the above results, it was interesting to apply small-angle X-ray scattering (SAXS) for investigation of phases formed by ds DNA CLCD doped with nano$\mathrm{Au}$. SAXS permits one to probe an internal structure of the object at resolution from about 1 to $100 \mathrm{~nm}$ and can provide valuable structural information both about nanoscale in homogeneities (particles or clusters) and about the internal ordering in the sample. The size and the shape of the scattering objects can be determined from the portion of the scattering pattern close to the primary beam (central scattering), while the internal structure is determined using information contained in scattering profiles at higher scattering angles and Bragg peaks [45-48].

Small-angle scattering curves of samples obtained from these phases are shown in Fig. (7). The cholesteric liquidcrystalline phase of the initial ds DNA was used as a control sample (curve 1). First of all, one can see that samples doped with nano-Au have diffuse Bragg maxima. Comparison of these curves shows that the interhelical distance (d) [4] 


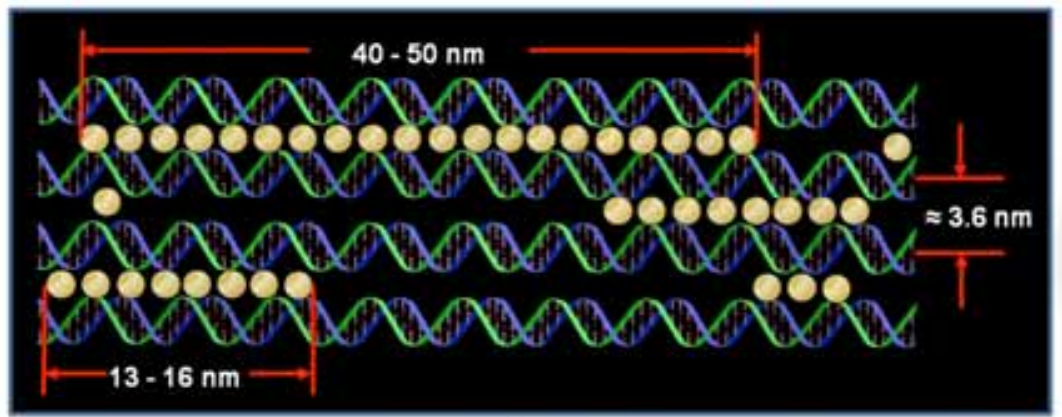

A

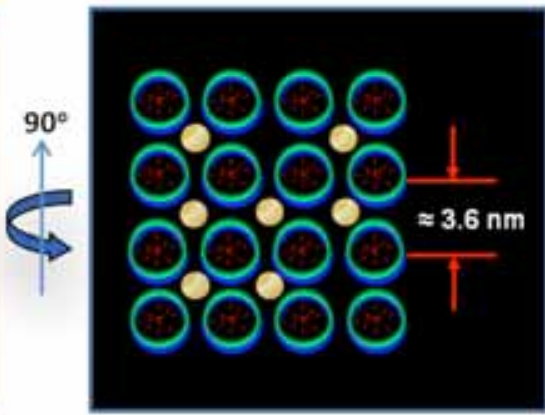

B

Fig. (8). Hypothetical model of location of linear Au-clusters in the "free" space between DNA molecules forming quasinematic layers in structure of CLCD.

$\mathrm{A}$ - side view; $\mathrm{B}$ - end view.

between neighboring ds DNA molecules in analyzed samples containing nano-Au remains unchanged in comparison to Au-free ds DNA CLCD sample. This means that the distance between neighboring quasinematic layers is unchanged as a result of the incorporation of nano-Au into structure of ds DNA CLCD. One can see that the concentration of ds DNA molecules remains constant and there is no transition due to the change in the concentration of ds DNA. Besides, one can see that the higher the nano-Au concentration in the sample, the lower the amplitude of the Bragg peaks due to their flattening and broadening, which indicates that the extent of the ordering is diminished. Taking into account the unchanged concentration of ds DNA molecules, this fact shows that the ordering of ds DNA molecules in neighboring quasinematic layers in CLCD particles is decreased. This result correlates with the $\mathrm{CD}$ spectra shown in Fig. (3), which gives evidence for a decrease in spatial ordering of ds DNA quasinematic layers upon increasing of nano-Au concentration [27]. Hence, one can claim that penetration of nano-Au into structure of quasinematic layers of ds DNA CLCD particles is a condition for collinear alignment of $\mathrm{ds}$ DNA molecules, and this process is accompanied by unwinding of helical structure of these particles. Finally, there is strong scattering at very small angles [49], i.e., in the region of the central scattering, which points to a presence of sufficiently large polydisperse scattering objects (nano-Au clusters).

The viewpoint on linear arrangement of nano-Au and the results of size calculation of nano-Au clusters made by the program GNOM [50] allow one to suggest a hypothetical model of fixation of nano-Au between ds DNA molecules in quasinematic layers (Fig. 8). According to this model, initial nano-Au molecules have average diameter (size) of about $2 \mathrm{~nm}$. These nano-Au form linear clusters with average length 13-15 $\mathrm{nm}$ and clusters with maximal length of $\sim 40$ $50 \mathrm{~nm}$. Formation of Au-clusters between ds DNA molecules strongly perturbs mutual orientation of neighboring quasinematic layers. As a result, the helical twisting of these layers in the structure of CLCD particles is decreased. Thus, data of SAXS speak in favor of the statement noted above. Namely, that the decrease in amplitude of abnormal band in CD spectrum of ds DNA CLCD reflects distortion in spatial arrangement of neighboring quasinematic layers induced by the formation of nano-Au clusters between them [51]. As a result of this process, spatial structure of CLCD particle loses its helical twisting and transition of "helically-twisted structure $\rightarrow$ untwisted structure" type is induced [7].

\subsubsection{AFM-images of "Rigid" Particles Formed by Doping of DNA CLCD with Nano-Au and Manipulations with Them}

As "rigid" DNA structure persists even in absence of high osmotic pressure of solution there is a possibility to investigate the concrete spatial details of this structure.

Fig. (9) shows the 2-D- and 3-D-images of ds DNA CLCD particles doped with nano-Au. The shape of "rigid" particles is close to the shape of elongated spherocylinders. One can see that this shape is very similar to the shapes of the "rigid" particles obtained as a result of creation of nanobridges between neighboring ds DNA molecules [3, 4]. The sizes of all types of "rigid" particles are varied from 0.1-0.2 $\mu \mathrm{m}$ to $0.7 \mu \mathrm{m}$ with $0.4-0.5 \mu \mathrm{m}$ as the average (inset in Fig. 9). This means that the initial size of the CLCD particles does not depend on the interaction of nano-Au with ds DNA forming the particles.

Fig. (9) confirms as well that ds DNA CLCD particles doped with nano-Au exist as independent, individual objects. This testifies that the "liquid" character of the DNA packing in the CLCD particles disappears and the formed particles have a "rigid" spatial structure.

Distinctive peculiarity of these "rigid" particles, in contrast to the "rigid" particles, which are obtained as a result of the ds DNA molecules cross-linking by various nanobridges, consists in a very weak binding affinity to the membrane filter. This fact opens up a new possibility for practical use of ds DNA CLCD particles doped with nano-Au. For instance, Fig. (10) demonstrates three "step-by-step" positions of a single ds DNA CLCD particle doped with nano-Au on the filter surface. One can see that close approaching of the AFM cantilever to this particle (its pushing by AFM cantilever) is accompanied by its translocation on surface of membrane filter and fixation in specific sites on the filter. This 

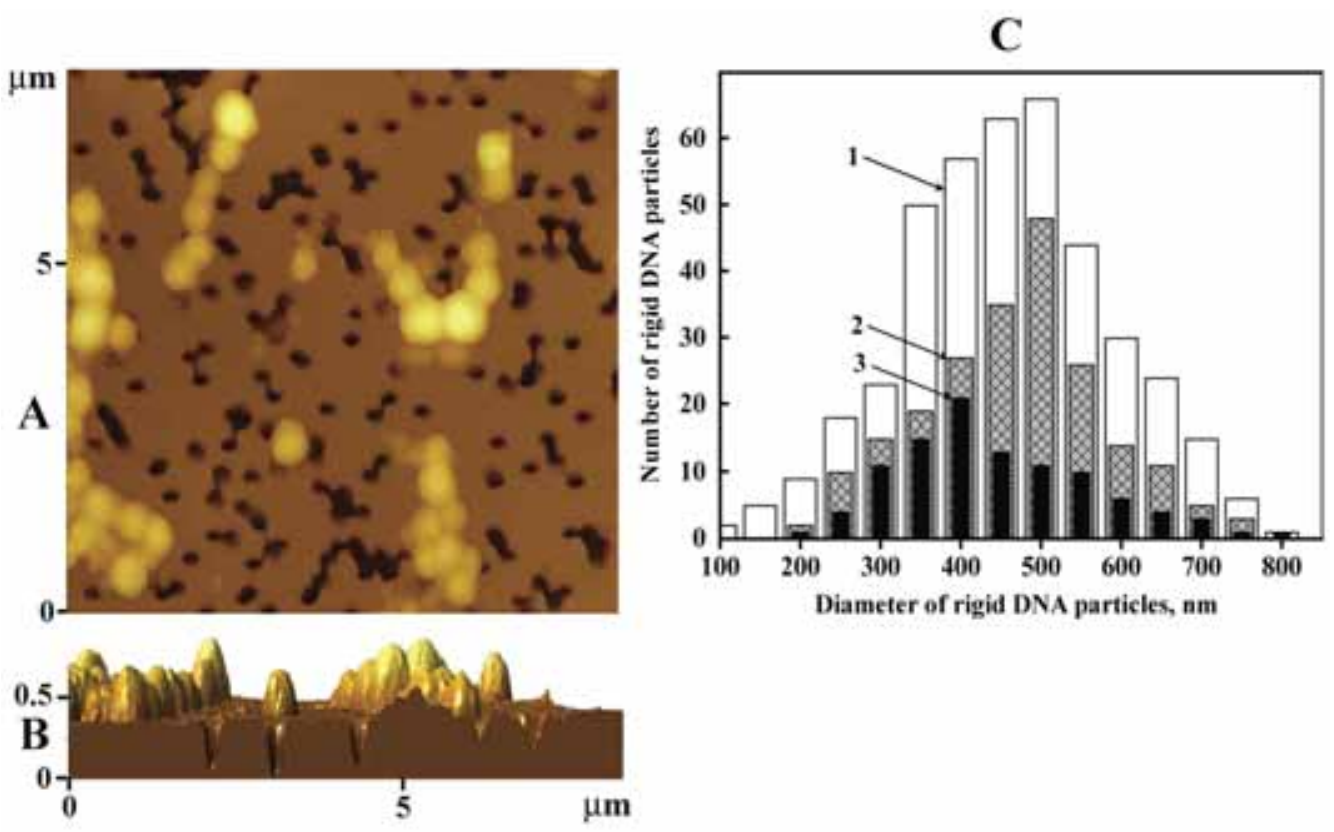

Fig. (9). 2-D (A) and 3-D (B) AFM images of "rigid" DNA particles formed as a result of doping of ds DNA CLCD with nano-Au. Dark spots are "pores" in nuclear membrane filter (PETP).

C - size distribution of "rigid" particles formed by ds DNA CLCD using various methods of these particle's creation:

1 - formation of nanobridges between ds DNA molecules;

2 - treatment with gadolinium salt;

3 - doping with nano-Au.
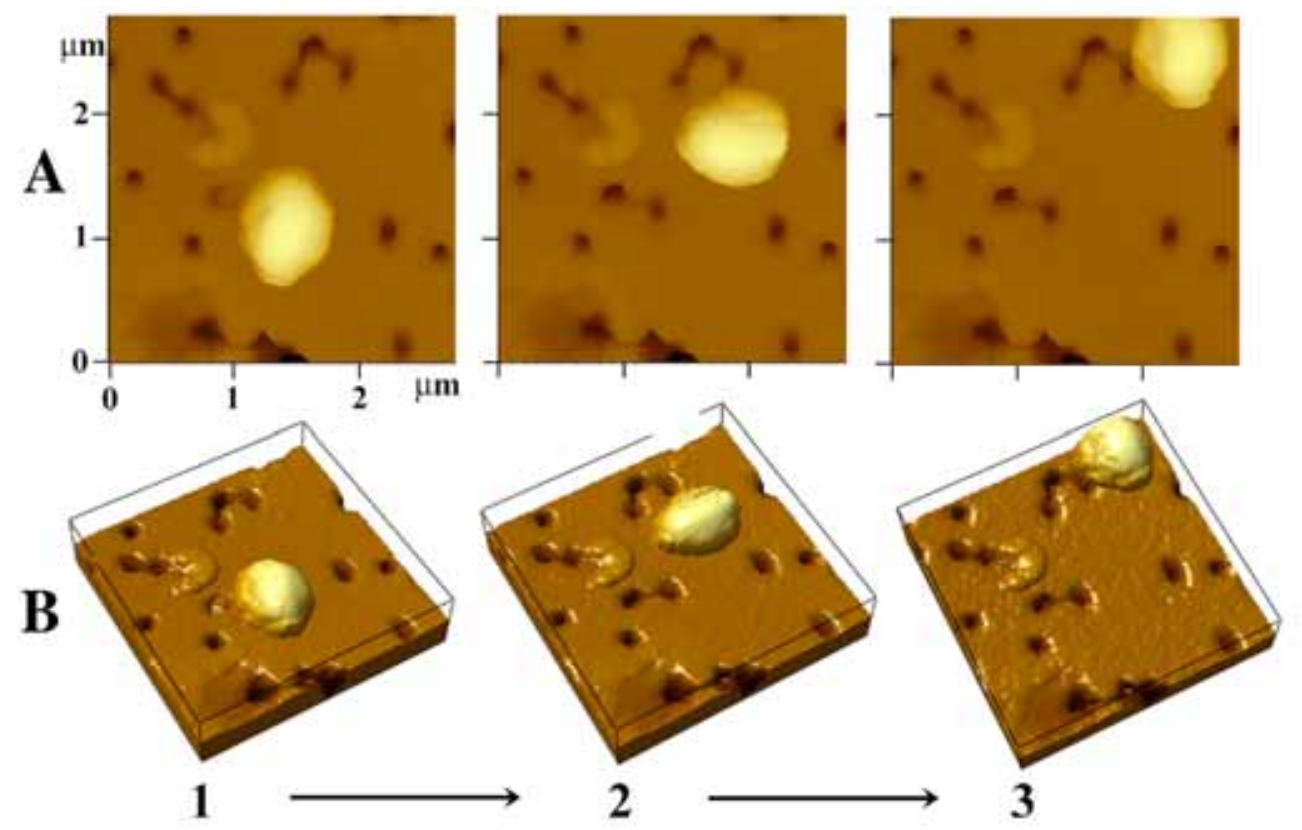

Fig. (10). Three consecutive positions of a single "rigid" DNA particle on membrane filter as a result of its pushing by AFM cantilever.

new result opens a possibility not only for the production of the cartoon to illustrate the translocation of "rigid" DNA particles, but for the creation of practically important matrices formed by the "rigid" DNA particles, which would have unique physicochemical properties.

Thus, doping of ds DNA molecules ordered in CLCD with nano-Au is accompanied by the physical gelation of these molecules and results in transformation of "liquid" DNA particles to their "rigid" state.

\section{CONCLUSION}

In this work we compare the physicochemical and nanotechnological approaches to the formation of "rigid" DNA particles (DNA NaCs). Various versions of the physicochemical approach are limited to "chemical gelation" of ds DNA molecules ordered in quasinematic layers of LCDs. Nanotechnology opens a new gate for "rigid" DNA NaCs formation. The data obtained demonstrate that doping of CLCD particles formed by high-molecular mass ds DNA 
molecules with nano-Au is accompanied by "physical gelation" of these molecules and results in two effects: i) it facilitates reorganization of the mutual orientation of neighboring quasinematic layers in initial ds DNA CLCD particles, and ii) induces the formation of extended linear nano-Au clusters between ds DNA molecules in CLCD particles. Under these conditions, parameters of helical twist of quasinematic layers are changed as it happens in the case of low molecular mass liquid crystals. Besides, "liquid" character of the ds DNA packing in CLCD particles disappears and formed particles have "rigid" spatial structure. Remarkable peculiarity of these "rigid" particles (DNA NaCs), in contrast to the "rigid" particles, which are obtained as a result of the ds DNA molecules chemical gelation, consists in a weak binding affinity to the membrane filter. This result opens a possibility not only for the production of the cartoon to illustrate the time translocation of "rigid" DNA particles, but also for the creation of practically important matrices formed by the "rigid" DNA particles, which would have unique physicochemical properties. The results of this study support the statement, according to which the distortion of mutual orientation of neighboring quasinematic layers formed by ds DNA molecule in spatial chromosome structure, induced by fixation of nano-Au between fragments of this molecule, can be one of the reasons for genotoxicity of these particles.

\section{CONFLICT OF INTEREST}

The authors confirm that this article content has no conflict of interest.

\section{ACKNOWLEDGEMENTS}

We would like to express our thanks to Mikhail N. Savvateev (AIST-NT Co., Zelenograd, Russia) for his technical assistance at the study of the "rigid" DNA particles by means of AFM. E.I. Kats gratefully acknowledges financial support from the Russian Science Foundation (grant 14-12-00475).

\section{REFERENCES}

[1] Minamisawa, Y.; Furusawa, K.; Yamamoto, T.; Dobashi, T. Monoand multilayered aluminum ion-induced liquid crystalline gel of DNA. Trans. Mater. Res. Soc. Jpn., 2006, 31, 739-741.

[2] Dobashi, T.; Furusawa, K.; Kita, E.; Minamisawa, Y.; Yamamoto, T. DNA liquid crystalline gel as adsorbent of carcinogenic agent. Langmuir, 2007, 23, 1303-1306.

[3] Yevdokimov, Yu.M.; Salyanov, V.I.; Skuridin, S.G. Nanostructures and DNA, Nanoconstructions based on DNA, CRC Press (Taylor \& Francis Group): Boca Raton- London-New-York, 2012.

[4] Yevdokimov, Yu.M.; Salyanov, V.I.; Semenov, S.V.; Skuridin, S.G. DNA Liquid- Crystalline Dispersions and Nanoconstructions. CRC Press (Taylor \& Francis Group): Boca Raton-London-New York, 2011.

[5] Dogic, Z.; Frenkel, D.; Fraden, S. Enhanced stability of layered phases in parallel hard spherocylinders due to addition of hard spheres. Phys. Rev. E., 2000, 62, 3925-3933.

[6] Belyakov, V.A.; Orlov, V.P.; Semenov, S.V.; Skuridin, S.G.; Yevdokimov, Yu.M. Comparison of calculated and observed CD spectra of liquid crystalline dispersions formed from doublestranded DNA and from DNA complexes with colored compounds. Liq. Crystals, 1996, 20, 777-784.

[7] Yevdokimov, Yu.M.; Salyanov, V.I.; Skuridin, S.G.; Semenov, S.V.; Kompanets, O.N. The CD Spectra of Double-Stranded DNA Liquid-Crystalline Dispersions. Nova Science Publishers: New York, 2011.
Leforestier, A.; Livolant, F. Supramolecular ordering of DNA in the cholesteric liquid crystalline phase. Biophys. J., 1993, 65, 5672 .

[9] Goldar, A.; Thomson, H.; Seddon, J.M. Goldar, A.; Thomson, H.; Seddon, J.M. Structure of DNA cholesteric spherulitic droplet dispersions. J. Phys. Condens. Matter, 2008, 20(3), 035102 (1-9).

[10] Tager, A.A. Physical Chemistry of Polymers (Russian Edition) Khimia: Moscow, 1978.

[11] Yevdokimov, Yu.M.; Salyanov, V.I.; Spener, F.; Palumbo, M. Adjustable "cross-linking" of neighboring DNA molecules in liquid-crystalline dispersions through (daunomycin- copper) polymeric chelate complex. Int. J. Biol. Macromol., 1996, 19, 247-255.

[12] Yevdokimov, Yu.M.; Salyanov, V.I.; Gedig, E.; Spener, F. Formation of polymeric chelate bridges between double-stranded DNA molecules fixed in spatial structure of liquid-crystalline dispersions. FEBS Lett., 1996, 393, 269-273.

[13] Nechipurenko, Yu.D.; Ryabokon, V.F.; Semenov, S.V.; Yevdokimov, Yu.M. Thermodynamic models describing the formation of "bridges" between molecules of nucleic acids in liquid crystals. Biophysics (Russian Edition), 2003, 48, 594-601.

[14] Yevdokimov, Yu.M.; Skuridin, S.G.; Nechipurenko, Yu.D.; Zakharov, M.A.; Salyanov, V.I.; Kurnosov, A.A.; Kuznetsov, V.D.; Nikiforov, V.N. Nanoconstructions based on double-stranded nucleic acids. Int. J. Biol. Macromol., 2005, 36, 103-115.

[15] Yevdokimov, Yu.M.; Sytchev, V.V. Nanotechnology and nucleic acids. Open Nanosci. J., 2007, 1, 19-31.

[16] Yevdokimov, Yu.M.; Salyanov, V.I.; Kondrashina, O.V.; Borshevsky, V.I.; Semenov, S.V.; Gasanov, A.A.; Reshetov, I.V.; Kuznetsov, V.D.; Nikiforov, V.N.; Akulinichev, S.V.; Mordovskoi, M.V.; Potashev, S.I.; Skorkin, V.M. Particles of liquid- crystalline dispersions formed by (nucleic acid-rare earth element) complexes as a potential platform for neutron capture therapy. Int. J. Biol. Macromol., 2005, 37, 165-173.

[17] Yevdokimov, Yu.M.; Salyanov, V.I.; Shtykova, E.V.; Dembo, K.A.; Volkov, V.V.; Spirin, P.V.; Slusheva, A.S.; Prassolov, V.S. A transition in DNA molecule's spatial ordering due to nano-scale structural changes. Open Nanosci. J., 2008, 2, 17-28.

[18] Shtykova, E.V.; Volkov, V.V.; Salyanov, V.I.; Yevdokimov, Yu.M. SAXS-data-based structural modeling of DNA-gadolinium complexes fixed in particles of cholesteric liquid- crystalline dispersions. Eur. Biophys. J., 2010, 39, 1313-1322.

[19] Lagerwall, J.P.F.; Scalia, G. A new era for liquid crystal research: Applications of liquid crystals in soft matter nano-, bio- and microtechnology. Curr. Appl. Phys., 2012, 12, 1387-1412.

[20] Liu, Q.; Cui, Y.; Gardner, D.; Li, X.; He, S.; Smalyukh, I. Selfalignment of plasmonic gold nanorods in reconfigurable anisotropic fluids for tunable bulk metamaterial applications. Nano Lett., 2010, 10, 1347-1353.

[21] Qi, H.; Hegmann, T. Liquid crystal-gold nanoparticle composites. Liq. Cryst. Today, 2011, 20, 102-114.

[22] Qi, H.; Kinkead, B.; Hegmann, T. Unprecedented dual alignment mode and Freedericksz transition in planar nematic liquid crystal cells doped with gold nanoclusters. Adv. Funct. Mater., 2008, 18, 212-221.

[23] Voloschenko, D.; Pishnyak, O.P.; Shiyanovskii, S.V.; Lavrentovich, O.D. Effect of director distortions on morphologies of phase separation in liquid crystals. Phys. Rev. E, 2002, 65, 060701 (1-4).

[24] Oswald, P.; Milette, J.; Relaix, S.; Reven, L.; Dequidt, A.; Lejcek, L. Alloy hardening of a smectic A liquid crystal doped with gold nanoparticles. Europhys. Lett., 2013, 103, 46004 (1-6).

[25] Draper, M.; Saez, I.M.; Cowling, S.J.; Gai, P.; Heinrich, B.; Donnio, B.; Guillon, D.; Goodby, J.W. Self-assembly and shape morphology of liquid-crystalline gold Metamaterials. Adv. Funct. Mater., 2011, 21, 1260-1278.

[26] Ao, G.; Nepal, D.; Aono, M.; Davis, V. Cholesteric and nematic liquid crystalline phase behavior of double-stranded DNA stabilized single-walled carbon nanotube dispersions. ACS Nano, 2011, 5, 1450-1458.

[27] Skuridin, S.G.; Dubinskaya, V.A.; Rudoy, V.M.; Dement'eva, O.V.; Zakhidov, S.T.; Marshak, T.L.; Kuzmin, V.A.; Popenko, V.I.; Yevdokimov, Yu.M. Effect of gold nanoparticles on DNA packaging in model systems. Dokla Biochem. Biophys. (Russian Edition), 2010, 432, 838-841.

[28] Mirkin, C.A.; Letsinger, R.L.; Mucic, R.C.; Storhoff, J.J. A DNAbased method for rationally assembling nanoparticles into macroscopic materials. Nature, 1996, 382, 607-609. 
[29] Alivisatos, P.A.; Johnsson, K.P.; Peng, X.; Wilson, T.E.; Loweth, C.J.; Bruchez, M.P.; Schultz, P.G. Organization of nanocrystal molecules using DNA. Nature, 1996, 382, 609-611.

[30] Herne, T.M.; Tarlov, M.J. Characterization of DNA probes immobilized on gold surfaces. J. Am. Chem. Soc., 1997, 119, 8916-8920.

[31] Jang, N.H. The coordination chemistry of DNA nucleosides on gold nanoparticles as a probe by SERS. Bull. Kor. Chem. Soc., 2002, 23, 1790-1800.

[32] Komarov, P.V.; Zherenkova, L.V.; Khalatur, P.G.; Khokhlov, A.R. The self-assembly of a metalloorganic nanoaggregate based on the electrostatic interaction between DNA molecule and gold nanoparticles polarized in its field. Russian Nanotechnologies (Russian Edition), 2007, 2, 92-98.

[33] Zherenkova, L.V.; Komarov, P.V.; Khalatur, P.G. Simulation of the metallization of a fragment of a deoxyribonucleic acid molecule with gold nanoparticles. Colloid Journal (Russian Edition), 2007, 69, 753-765.

[34] Dykman, L.; Bogatyrev, V.; Shchyogolev, S.; Khlebtsov, N. Gold Nanoparticles: Synthesis, Properties, Bio-medical Applications (Russian Edition). Nauka: Moscow, 2008.

[35] Louis, C.; Pluchery, O. Gold Nanoparticles for Physics. Chemistry and Biology. Imperial College Press: London, 2012.

[36] Park, S.J.; Lazarides, A.A.; Mirkin, C.A.; Brazis, P.W.; Kannewurf, C.R.; Letsinger, L. The electrical properties of gold nanoparticle assemblies linked by DNA. Angew. Chem. Int. Ed., 2000, 39, 3845-3848.

[37] Sastry, M.; Kumar, A.; Datar, S.; Dharmadhikari, C.V.; Ganesh, K.N. DNA-mediated electrostatic assembly of gold nanoparticles into linear arrays by a simple drop-coating procedure. Appl. Phys. Lett., 2001, 78, 2943-2945.

[38] Kumar, A.; Pattarkine, M.; Bhadbhade, M.; Mandale, A.B.; Ganesh, K.N.; Datar, S.S.; Dharmadhikari, C.V.; Sastry, M. Linear superclusters of colloidal gold particles by electrostatic assembly on DNA templates. Adv. Mater., 2001, 13, 341-344.

[39] Warner, M.G.; Hutchison, J.E. Linear assemblies of nanoparticles electrostatically organized on DNA scaffolds nature materials. $\mathrm{Na}$ ture Mater., 2003, 2, 272-277.
[40] Storhoff, J.J.; Lazarides, A.A.; Mucic, R.C.; Mirkin, C.A.; Letsinger, R.L.; Schatz, G.C. What controls the optical properties of DNA-linked gold nanoparticle assemblies? J. Am.Chem. Soc., 2000, 122, 4640-4650.

[41] Lifshitz, I.M.; Slyozov, V.V. The kinetics of precipitation from supersaturated solid solutions. J. Phys. Chem. Solids, 1961, 19, 3550 .

[42] Khlebtsov, N.G. T-matrix method in plasmonics. J. Quant. Spectr. Radiat. Transfer., 2013, 123, 184-217.

[43] Khlebtsov, N.G.; Melnikov, A.G.; Dykman, L.A.; Bogatyrev, V.A. Optical properties and biomedical applications of nanostructures based on gold and silver bio-conjugates. Photopolarimetry in remote sensing. In: G. Videen, Ya.S. Yatskiv and M.I. Mishchenko, Eds., NATO Sci Ser, II. Math, Phys. Chem., 2004, 161, 265-308.

[44] Khlebtsov, B.N.; Zharov, V.P.; Melnikov, A.G.; Tuchin, V.V.; Khlebtsov, N.G. Optical amplification of photothermal therapy with gold nanoparticles and nanoclusters. Nanotechnology, 2006, 17, 5167-5179.

[45] Guinier, A.; Fournet, G. Small-Angle Scattering of X-Rays. John Wiley and Sons: New York, 1955

[46] Glatter, O.; Kratky, O. Small-Angle X-Ray Scattering. Academic Press: London, 1982.

[47] Feigin, L.A.; Svergun, D.I. Structure Analysis by Small-Angle XRay and Neutron Scattering. Plenum Press: New York, 1987.

[48] Mertens, H.D.; Svergun, D.I. Structural characterization of proteins and complexes using small-angle X-ray solution scattering. $J$. Struct. Biol., 2010, 172, 128-141.

[49] Yevdokimov, Yu.M.; Skuridin, S.G.; Salyanov,V.I.; Popenko, V.I.; Rudoy,V.M.; Dement'eva, O.V.; Shtykova, E.V. A dual effect of Au-nanoparticles on nucleic acid cholesteric liquid-crystalline particles. J. Biomater.Nanobiotechnol. 2011, 2, 461-471.

[50] Svergun, D.I.; Semenyuk, A.V.; Feigin, L.A. Small-anglescattering-data treatment by the regularization method. Acta Cryst., 1988, A44, 244-250.

[51] Yevdokimov, Yu.M.; Shtykova, E.V.; Salyanov, V.I.; Skuridin, S.G. Linear clusters of gold nanoparticles in quasinematic layers of DNA liquid-crystalline dispersion particles. Biophysics (Russian Edition), 2013, 58, 210-220.

Received: December 18, 2013

Revised: May 19, 2014

Accepted: May 20, 2014

(C) Yevdokimov et al.; Licensee Bentham Open.

This is an open access article licensed under the terms of the Creative Commons Attribution Non-Commercial License (http://creativecommons.org/licenses/by-nc/3.0/) which permits unrestricted, non-commercial use, distribution and reproduction in any medium, provided the work is properly cited. 